\title{
Session 1793
}

\section{A NEW LEARNING ENVIRONMENT USING REUSABLE, INTERACTIVE LEARNING OBJECTS IN AN ENGINEERING DIGITAL LIBRARY: THE GROW-NCERL PROJECT}

\author{
Muniram Budhu \\ Professor, Department of Civil Engineering \& Engineering Mechanics, University \\ of Arizona, Tucson, AZ, 85721 USA. E-mail: budhu@u.arizona.edu
}

\begin{abstract}
INTRODUCTION
Libraries have always played a key role in education. They provide a place for the storage and retrieval of a large body of human knowledge. Digital technologies are now transforming and expanding the traditional roles of library. Digital libraries provide an assortment of tools for a user to search, retrieve, create, customize and share content that are available anytime, anyplace. Teachers, students and faculty can now utilize the environment provided by digital libraries to transform the way we teach and learn. Various contents can now be shared, integrated and customized to enhance learning. Educators are no longer tied to static graphics and text but can customize media-rich (interactive visualizations, simulations, speech, sound, text, etc.) content from a large repository to produce dynamic, engaging educational materials.

Delivery of instructional materials is no longer confined to real estate and scheduling but can be delivered anytime, any place using a variety of digital devices - desktop and laptop computers, PC Tablets, mobile phones, PDAs, webpads and consoles. Users can form on the spot communities or continual communities of learners for collaborative learning.
\end{abstract}

The purpose of this paper is to describe the development of a digital library for civil engineering, the creation of learning objects at different levels of granularity and a potential new learning environment for engineering education. A key attribute of these learning objects is metadata tagging that enables these objects to be searched, retrieved and customized for different learners.

\section{THE GROW-NCERL DIGITAL LIBRARY PROJECT}

The US National Science Foundation is funding the creation of a National Science, Mathematics, Engineering and Technology Digital Library (NSDL; http://www.nsdl.org/). NSDL is a central system of integrating various digital libraries, each with a collection of digital objects in a specific field of information. NSDL provides information services and universal access to high quality educational resources. One of the digital libraries within NSDL is the Geotechnical, Rock and Water Resources Engineering Digital Library (GROW; www.grow.arizona.edu). 
GROW is the first phase of a National Civil Engineering Educational Resources Library (NCERL). The resources in GROW are collected from the Web, created by developers at the University of Arizona, and contributed by users. The emphasis in this paper is the potential use of GROW as a learning environment. This environment allows a student to learn from rich interactive learning objects. Learning objects have several definitions in the literature. In this paper, a learning object is "any digital resource that can be reused to support learning" [1]. Each learning object within a group have properties that allow it to be reusable, self-contained, aggregated and tagged with metadata (http://www.wisc-online.com/Info/FIPSE\%20\%20What $\% 20$ is\%20a\%20Learning\%200bject.html

GROW learning objects are intended to make a paradigm shift from linear, static, text-based oriented course material to non-linear, dynamic, visually oriented material. Non-linearity widens the knowledge landscape and allows a student, if he/she prefers, to get related materials on the World Wide Web.

Research in education reveals that students learn best when they are actively engaged with their learning [2]. This engagement challenges students' ideas, exposes their misconceptions, and helps them to see what they have not seen before. Students are engaged when they believe that they are part of a community of learners. The design of the GROW projects include multiple opportunities for students to work together, to design, to be challenged, and to be members of a group that work to solve problems.

\section{LEARNING OBJECTS AND ENVIRONMENT}

Pedagogy of the learning objects follow those proposed by Gagné [3], Clark [4], Felder and Silverman [5] and includes gaining attention, informing students of the objective, stimulating recall of prior knowledge, presenting the stimulus, providing learning guidance, eliciting performance, providing feedback, assessing performance, enhancing retention and transfer of learning. Each learning object belongs to a hierarchical class called a theme - a collection of learning objects that addresses a global topic [6]. To illustrate the hierarchy and the learning environment, three learning objects, called modules hereon, will be briefly demonstrated. The theme is the effects of water on soils. In the first module, http://www.grow.arizona.edu/geotechnical/effects_of_water/claynwater.shtml, lowest level in the hierarchy, our objective is for students to learn about the changes in the soil state when water is added continuously. Figure 1a illustrates a screen shot of a piece of soil and a slider that the student moves with a mouse to increase the water content. As water is added to the solid soil, it becomes softer and the student not only sees this change but also is informed on the use of soil at that state. For example, after a certain amount of water is added, the soil can be molded without cracking and at this stage the soil can be used to make pottery (Figure 1b). This module is suitable for middle and high school students as well as undergraduates. But how do we find out how much water is in the soil? 


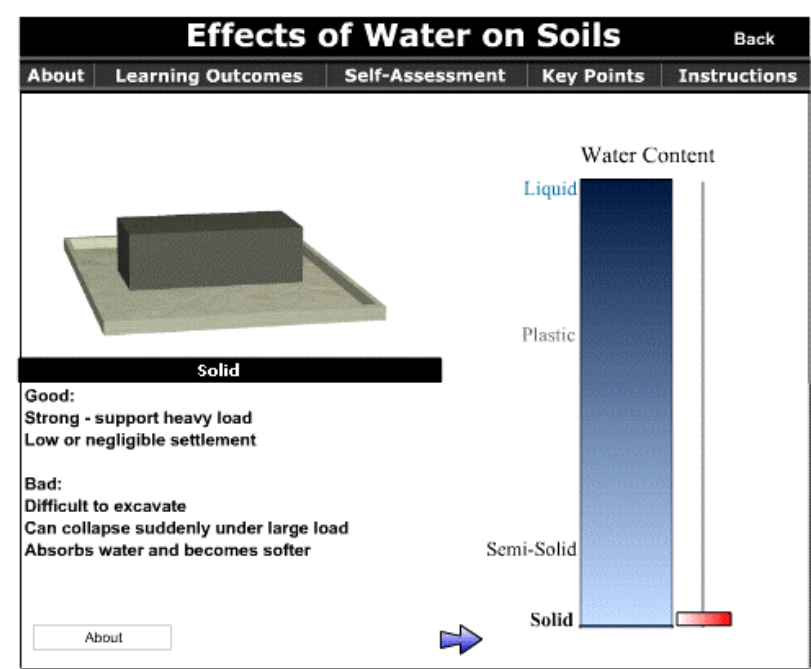

(a)

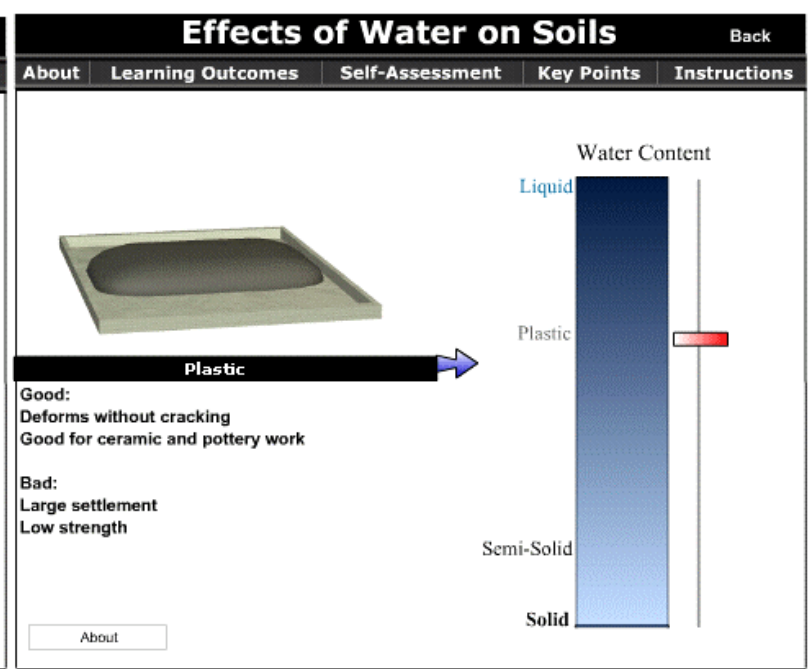

(b)

Figure 1 Two screen shots from a module showing changes in soils states

A second module allows the student to conduct a virtual lab experiment (http://www.grow.arizona.edu/geotechnical/effects_of_water/soilwatercontent.shtml) selecting from among various soil types (Figure 2a). Figure $2 b$ illustrates one stage of the experiment in which the student is prompted to move the cup containing the wet soil to the scale and once that is done the weight is shown. The experiment continues interactively with the student placing the wet soil in an oven and is completed when the student calculates the water content and then answers a quiz to test short-term knowledge retention. The student can then select a different soil and repeat the experiment to compare the water retention capacity of different soil types. An experiment on a single soil type as described above will take about 24 hours in a physical lab but on the computer its takes less than 5 minutes and the student obtains all the required knowledge. A physical experiment can then be conducted for the student to get the feel of a real soil and operating in a physical lab if laboratory facilities are available.

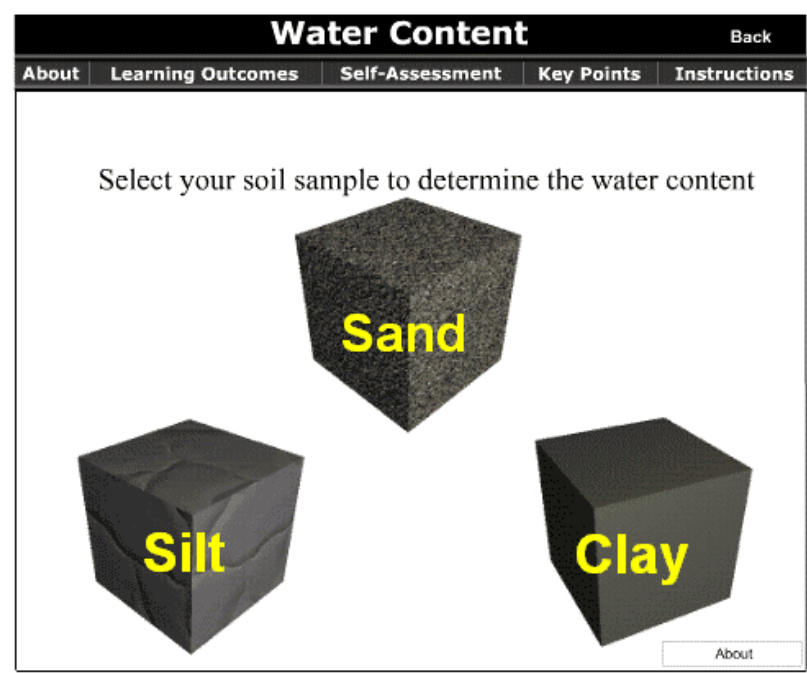

(a)

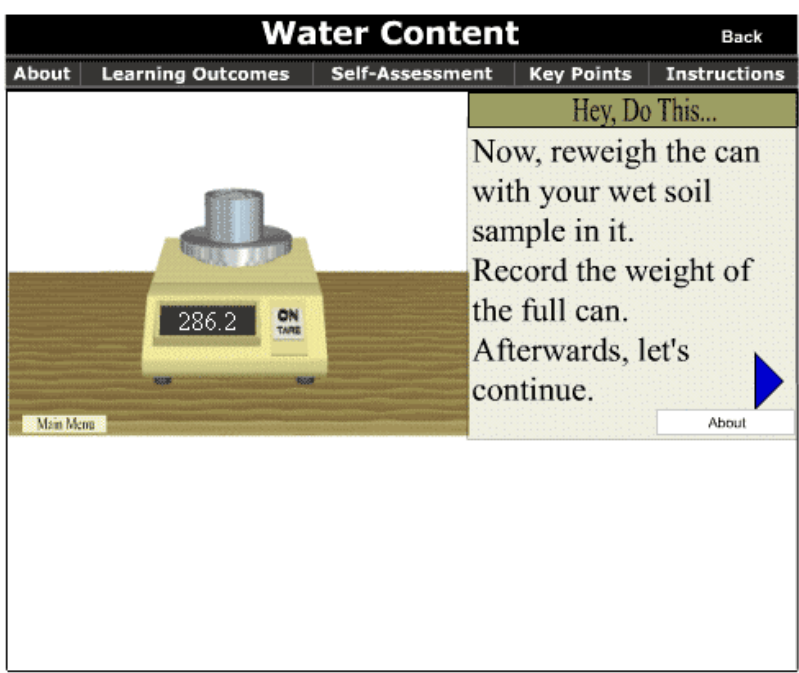

(b)

Figure 2 (a) Soil selection screen and (b) Weighing of can and wet soil

Proceedings of the 2004 American Society for Engineering Education Annual Conference \& Exposition

Copyright@2004, American Society for Engineering Education 
This virtual lab module is suitable for middle and high school students as well as undergraduates. The next module up the hierarchy is a module that is suitable for undergraduates in civil engineering students taking a course in soil mechanics. Here the objectives are (1) to learn about the different soil phases (2) to know the name of the limiting water contents at which each phase change occurs (3) to be able to calculate the plasticity index and the liquidity index and (4) to be able to identify some qualitative engineering properties of each phase.

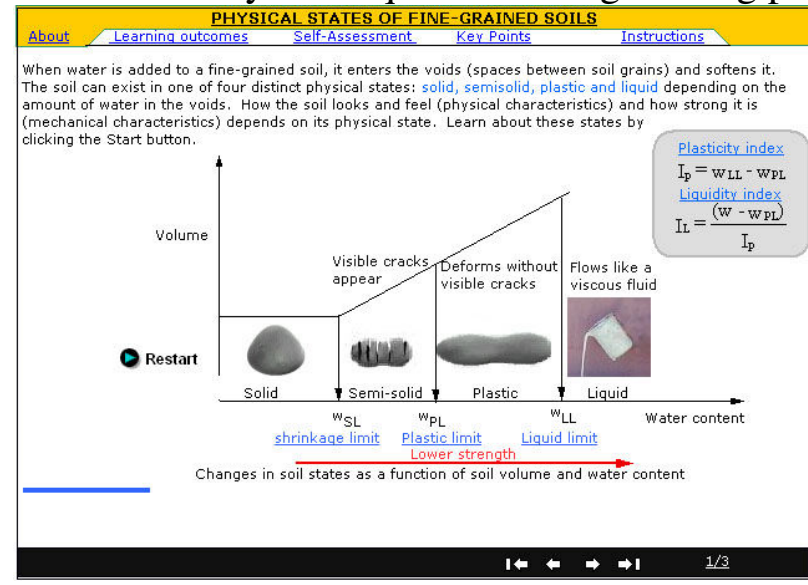

(a)

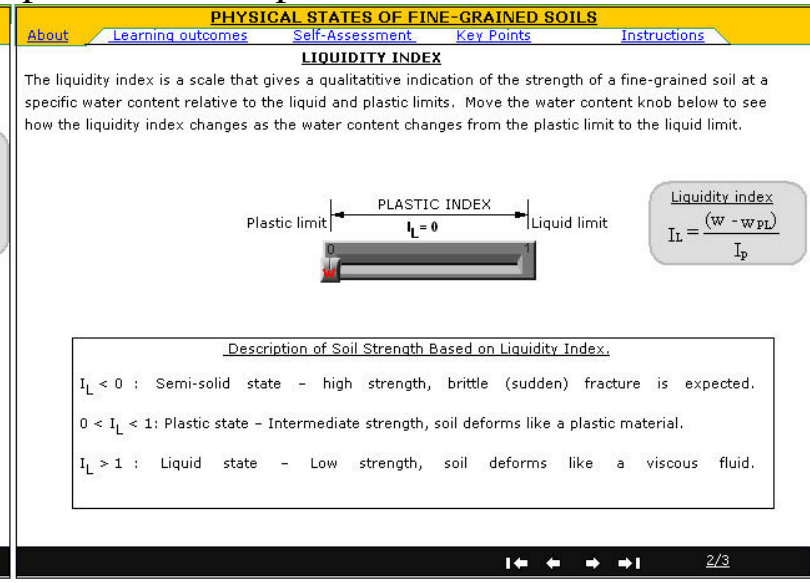

(b)

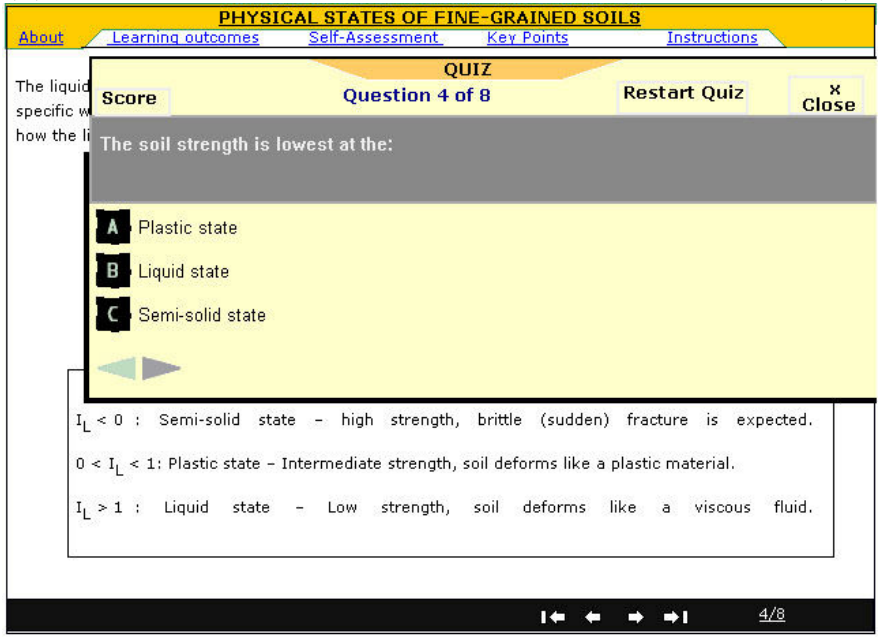

(c)

Figure 3 Three screen shots of the physical states module

In Figure 3(a) the student interacts with an animation that shows the changes in soils states and the volume changes as the water content is increased. The water content at each phase transformation is shown and is linked to further information. The student can then click these links to get more detail information. In Figure 3(b) the student explores the liquidity index parameter (page 2 of the module) as the intact water content of the soil changes by interacting with a slider bar. In Figure 5(c) the student answers a quiz to test short-term knowledge retention. Further higher-level modules are available in this theme.

An instructor can manipulate these modules, e.g. changing the learning outcomes, and used them in other learning situation. For example, an instructor may want to discuss mudslides. He/she 
and the students may use the first two models described and then show a mudslide module as depicted in Figure 4.

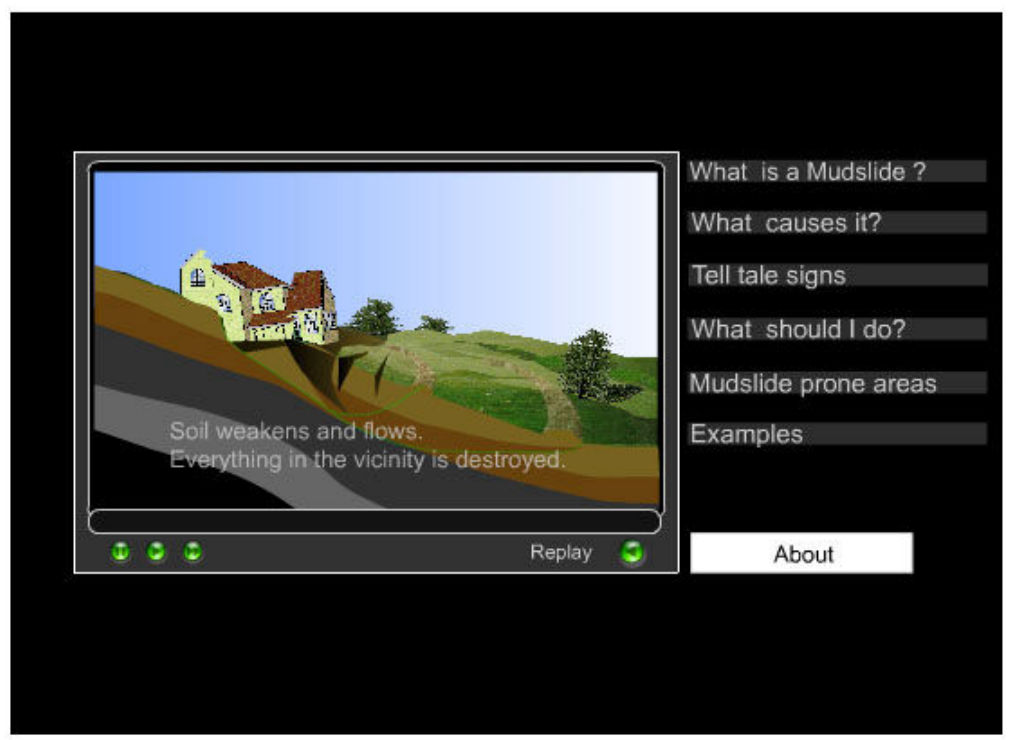

Figure 4 A screen shot of a mudslide module

\section{METADATA TAGGING, USER SERVICES AND PEER REVIEW}

One of the keys to success of a digital library and the reusability of learning objects is standard metadata tagging. GROW metadata scheme is the international standard Dublin Core with education elements dubbed DC-Ed Qualified. In addition, 4 elements from the IEEE Learning Object Metadata (LOM) framework to tag interactivity, and an additional element called Keywords (www.grow.arizona.edu) are used [6]. A total of 20 fields (title, description, interactivity level, etc) are used to identify each object. A complete list of fields is available at http://www.grow.arizona.edu/ A contributor of resources completes about 4 fields and other fields are completed by GROW cataloging team to ensure accuracy. Figure 5 illustrates the metadata entry process.

Resources by GROW team members are tagged internally with all fields. All the digital library projects within NSDL are using standard metadata schemes with most using the DC or DC-Ed Qualified standard. This commonality in metadata tagging allows NSDL to readily harvest resources from all of the digital libraries. A user can locate resources in all the libraries through NSDL (www.nsdl.org) or through individual digital libraries like GROW. GROW also provides search, contribute and customization services to its users.

Presently, each object is reviewed by an internal team consisting of students and faculty knowledgeable in the subject matter before they are placed on the GROW site. An external peer review process has been be implemented following the process shown in Figure 6 . In addition to these two review processes, users can submit reviews of objects and services that are accessed. A ranking scheme based on the three reviews (internal, external peer and user) are attached to each object. 


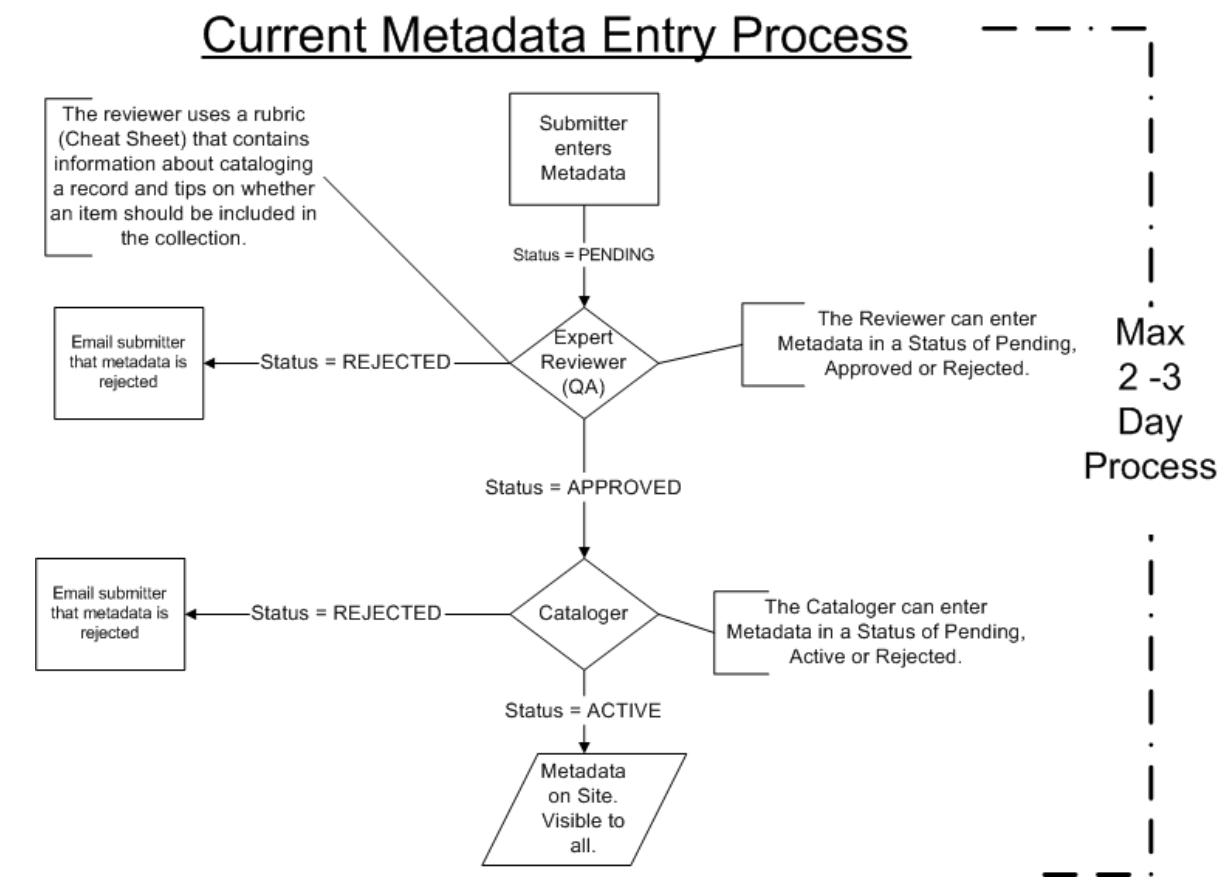

Figure 5 Metadata entry process

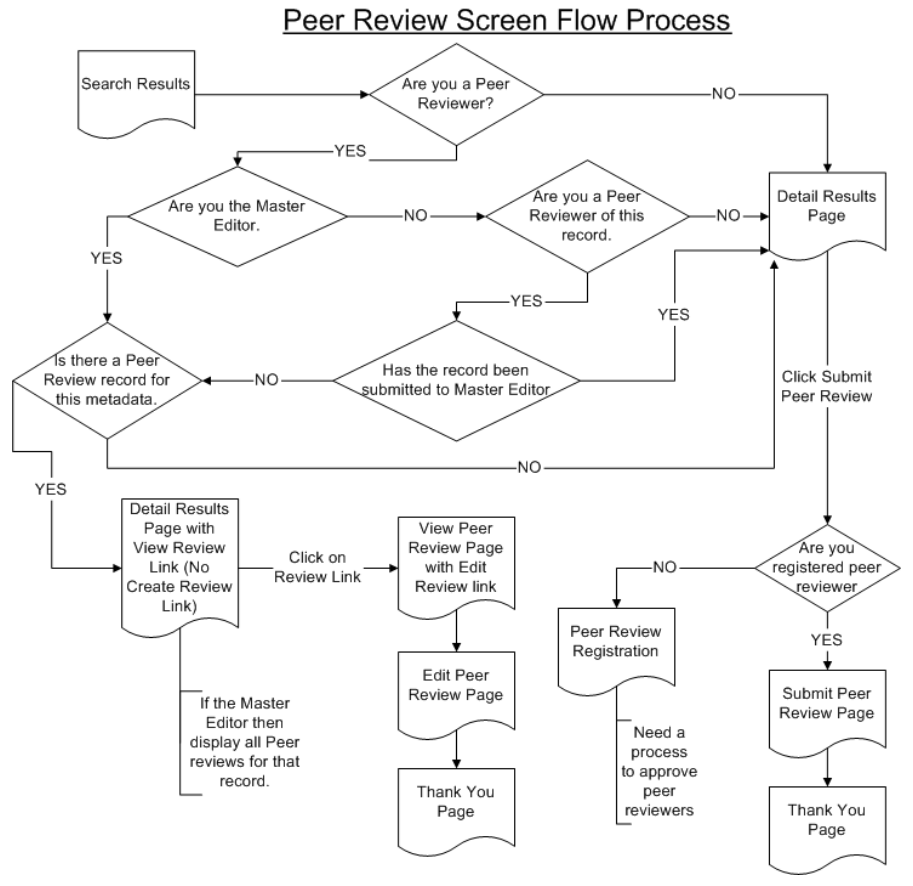

Figure 6 Peer review process

\section{CONCLUSIONS}

Digital resources within GROW-NCERL and NSDL as a whole have the potential to provide a new learning environment and enhance engineering education. They expand the role of libraries from a repository and accessible source of information to one in which a user can receive

Proceedings of the 2004 American Society for Engineering Education

Annual Conference \& Exposition

Copyright@2004, American Society for Engineering Education 
educational instructions anyplace, anytime. Learning objects that are tagged using standard metadata scheme allow them to be searched, retrieved, reused and re-purposed for education. The usefulness of the resources in GROW-NCERL and other digital libraries will only be known after several years of use.

\section{ACKNOWLEDGEMENT}

GROW-NCERL is funded from a National Science Foundation (NSF) grant \#DUE-0121691. The help of Dr. Lee Zia, NSF program manager, is gratefully acknowledged. Some of the resources on the GROW-NCERL web site were developed under NSF grant \#DUE-9950906. More information on GROW-NCERL is available at http://www/grow.arizona.edu

\section{REFERENCES}

[1] Wiley, D. A. Connecting learning objects to instructional design theory: A definition, a metaphor, and a taxonomy, in D. A. Wiley, ed., The Instructional Use of Learning Objects: Online Version, http://reusability.org/read/chapters/wiley.doc, 2000.

[2] How People Learn, National Research Council, 2000.

[3] Gagné, Robert (1995) The conditions of learning, Holt, Rinehart and Wilson, NY.

[4] Clark, R. C. (1989) Developing Technical Training, Buzzards Bay Press, Phoenix, AZ.

[5] Felder, R. M. and Silverman, L. K. (1988) Learning and Teaching Styles, Engineering Education, April Issue, pp. 674-681

[6] Budhu, Muniram and Coleman, Anita. The Design and Evaluation of Interactivities in a Digital Library, D-Lib Magazine, Nov.

http://www.dlib.org/dlib/november02/coleman/11coleman.html, 2000.

\section{BIOGRAPHICAL INFORMATION}

Muniram Budhu received a BSc in Civil Engineering with First Class honors from the University of the West Indies, Trinidad and a Ph.D from Cambridge University, England. Dr. Budhu has wide research interests and has published articles dealing with a variety of subjects including engineering mechanics, soil mechanics, soil dynamics, foundations, hydraulics, geoenvironmental engineering and applications of modern communication technologies in engineering education. 